\title{
Analysis Denitration Technology for Iron-steel Sintering Flue Gas
}

\author{
Shaohua Ling ${ }^{1, *}$, Changyong Jing $^{1}$ and Lijuan Zhang ${ }^{1}$ \\ 1,Department of Environment Engineerring, Environmental Management College of China, Qinhuangdao,HeBei,China
}

\begin{abstract}
This paper analyzes and discusses the flue gas denitrification technology in the application of sintering flue gas,combining the characteristics of the steel industry sintering flue.To $400 \mathrm{~m}^{2}$ sintering machine,study on sintering flue gas ozone oxidation simultaneous desulfurization and denitrification technology plan,and analyzes environmental and economic benefits for sintering flue gas ozone oxidation simultaneous desulfurization and denitrification Technology.
\end{abstract}

\section{Foreword}

With the promulgation of "Steel sintering and pelletizing industry air pollutant emission standards" (GB 286622012), the $\mathrm{NO}_{\mathrm{X}}$ concentration of the Steel sintering flue gas must be less than $300 \mathrm{mg} / \mathrm{m}^{3}$ since January $1,2015^{[1]}$. Sintering industry as a major source of emissions of the steel industry,facing a severe situation of flue gas denitration.In this paper,in connection with the characteristics of sintering flue gas,discusse denitrification technology for sintering flue gas,study on sintering flue gas ozone oxidation simultaneous desulfurization and denitrification technology plan,and analyze the economic and environmental benefits of ozone oxidation simultaneous desulfurization and denitrification technology plan.

\section{The Characteristics of Sintering Flue Gas}

\subsection{The source of nitrogen oxides in the sintering flue gas}

$\mathrm{NO}_{\mathrm{X}}$ emissions is from flue gas of the head of sintering machine.Nitrogen in th fuel or air reacts with oxygen, the reaction product is $\mathrm{NO}_{\mathrm{X}}$, including the thermal type $\mathrm{NO}_{\mathrm{X}}$, fuel type $\mathrm{NO}_{\mathrm{X}}$ and fast type $\mathrm{NO}_{\mathrm{X}}{ }^{[2]}$.

Thermal type $\mathrm{NO}_{\mathrm{X}}$ is that during sintering process, $\mathrm{N}_{2}$ and $\mathrm{O}_{2}$ in the air reacts $\mathrm{NO}_{\mathrm{X}}$ at high temperatures. Thermal $\mathrm{NO}_{\mathrm{X}}$ is proportional to $\mathrm{N}_{2}, \mathrm{O}_{2}$ concentration and reaction temperature. When the combustion temperature exceeds $1000{ }^{\circ} \mathrm{C}$, thermal $\mathrm{NO}_{\mathrm{X}}$ began to increase, when the combustion temperature exceeds $1500{ }^{\circ} \mathrm{C}$, thermal $\mathrm{NO}_{\mathrm{X}}$ increases significantly.Sintering process commonly used blast combustion, the bed temperature is between $1100-1400^{\circ} \mathrm{C}$.In this condition, the reaction rate of $\mathrm{N}_{2}$ and $\mathrm{O}_{2}$ is slow.Large and medium sized iron and steel enterprises of domestic have basically adopted the low temperature sintering production technology, the maximum temperature of sintering flue gas is less than $1300{ }^{\circ} \mathrm{C}$. Therefore,small amounts of thermal $\mathrm{NO}_{\mathrm{X}}$ is generated during the sintering process.

Fuel $\mathrm{NO}_{\mathrm{X}}$ is that during sintering process, nitrogen in the fuel reacts with oxygen in the air, generate NOx.

Rapid type $\mathrm{NO}_{\mathrm{X}}$ is that during sintering process, hydrocarbons in the fuel reacts rapidly with $\mathrm{N}_{2}$ in the air at a high temperature flame,generate $\mathrm{NO}_{\mathrm{X}}$. Since the generation amount is small, generally not considered.

So $\mathrm{NO}_{\mathrm{X}}$ in the flue gas of the sintering process mainly is fuel $\mathrm{NO}_{\mathrm{X}}$.

\subsection{The characteristics of sintering flue gas}

Because the sintering process is long,the kind of fuel and raw materials is more,firing conditions and temperature changes,sintering flue gas is different with the general combustion flue gases. The main features of sintering flue gas as follows ${ }^{[3]}$.

Flue gas volume is large.Since the air leakage rate and solids circulation rate is high, there is a considerable part of the air does not pass the sinter layer,so sintering flue gas is greatly increased.Each producing $1 \mathrm{t}$ sinter, sintering flue gas generation amount is $4000-6000 \mathrm{~m}^{3}$.Currently the average size of new sintering machine production is 379 $\mathrm{m}^{2}$,and there are further large-scale trend.Therefore flue gas volume of large-scale sintering could reach 2-3 million $\mathrm{m}^{3} / \mathrm{h}$.

Flue gas temperature is fluctuate.With different sintering conditions, flue gas temperature in the range of $120-180^{\circ} \mathrm{C}$.

$\mathrm{NO}_{\mathrm{X}}$ concentration of flue gas is low. $\mathrm{NO}_{\mathrm{X}}$ concentration is generally in the range of 200-400 $\mathrm{mg} / \mathrm{m}^{3}$, instantaneous concentration is up to $650 \mathrm{mg} / \mathrm{m}^{3}$.

Dust concentration of flue gas is high.Dust is mainly iron and its compounds.Due to the use of different materials may also contain trace amounts of heavy metal elements.Dust concentration in the flue gas is generally up to $10 \mathrm{~g} / \mathrm{Nm}^{3}$, the average particle diameter of dust is $13-35 \mu \mathrm{m}$.

The moisture content is large.In order to increase the permeability of the sinter bed,water was added to the mixture before sintering. Moisture content is generally about $10 \%$.

The oxygen content is high.General oxygen content of sintering flue gas is $12 \%$ to $18 \%$.

$\mathrm{SO}_{2}$ concentration of flue gas is relatively low. With the sulfur content of different raw materials, $\mathrm{SO}_{2}$ concentration of sintering flue gas of domestic enterprises generally is $1000-3000 \mathrm{mg} / \mathrm{m}^{3}$.

Containing harmful gases.Flue gas not only contains $\mathrm{SO}_{2}$ and $\mathrm{NOx}$, but also contains a certain amount of $\mathrm{HCl}$ and $\mathrm{HF}$,etc. 


\section{Sintering flue gas denitrification technology}

\subsection{Selective Catalytic Reduction (SCR)}

Selective catalytic reduction (SCR) is that ammonia as a reducing agent to remove the $\mathrm{NO}_{\mathrm{X}}$ of exhaust.Under the effect of a certain temperature and catalyst, $\mathrm{NO}$ reacts with $\mathrm{NH}_{3}, \mathrm{NO}_{\mathrm{X}}$ will be reduced to $\mathrm{N}_{2}$, while generating water ${ }^{[4-5]}$. Use of the catalyst can reduce the activation energy of the reaction,so the reaction temperature was lowered to $350-420^{\circ} \mathrm{C}$. The process is a practical method capable of removing NOx in an oxidizing atmosphere.NOx removal rate of the process up to $90 \%$.Sintering flue gas temperature is generally $120-180{ }^{\circ} \mathrm{C}$, using the above method to remove $\mathrm{NO}_{\mathrm{X}}$ of flue gas, sintering flue gas must be heated to the reaction temperature.Power consumption is large,the economy is poor.So SCR denitration process in sintering flue gas is difficult.

\subsection{Activated carbon adsorption process}

Principle of activated carbon adsorption process is that sintering flue gas is sent to activated carbon adsorption tower,and ammonia is add at the entrance of the tower adsorption. $\mathrm{SO}_{2}$ and $\mathrm{NO}_{\mathrm{X}}$ of flue gas react with $\mathrm{NH}_{3}$ in the adsorption tower, the resulting ammonium salt is removed by activated carbon adsorption.Activated carbon adsorption of ammonium salt is sent to desorption tower. When activated carbon is heated to about $400{ }^{\circ} \mathrm{C}, \mathrm{SO}_{2}$ of high concentrations can be desorbed. Desorbed $\mathrm{SO}_{2}$ can be used to produce high-purity sulfur or sulfuric acid.Regenerated activated carbon be cooled and removed impurities,returned to the absorber for recycling.Activated carbon adsorption process not only can remove $\mathrm{SO}_{2}$ and $\mathrm{NO}_{\mathrm{X}}$ of the flue gas, but also can remove $\mathrm{HCl}, \mathrm{HF}, \mathrm{As}, \mathrm{Hg}$ and other trace substances of the flue gas.But the investment and operating costs of such a process is too high, the economy is poor,so it could not be replicated in the steel industry.

\subsection{Selective non-catalytic reduction (SNCR)}

Selective non-catalytic reduction (SNCR) is that reaction temperature is $900-1100{ }^{\circ} \mathrm{C}$, without the presence of catalyst,ammonia or urea selectively reduce with $\mathrm{NO}_{\mathrm{X}}$ of the flue gas, the reaction product was $\mathrm{N}_{2}$ and $\mathrm{H}_{2} \mathrm{O}^{[67]}$.In the sintering industry, there is no suitable temperature ranges for SNCR denitration.So SNCR denitration technology is unsuitable in sintering flue gas denitration.

\subsection{0zone oxidation simultaneous desulfurization and denitrification technology}

Ozone oxidation simultaneous desulfurization and denitrification technology is that $\mathrm{NO}$ is oxidized to $\mathrm{NO}_{2}$ by ozone, $\mathrm{NO}_{2}$ and $\mathrm{SO}_{2}$ is absorbed along with $\mathrm{Ca}(\mathrm{OH})_{2}$ or $\mathrm{CaO}$,to achieve the goal of simultaneous desulfurization and denitrification.Using this technique,we can make full use of the existing desulfurization equipment for sintering,denitrification equipment without a separate building,saving equipment investment,reducing the cost of flue gas pollutant emission control.Denitration facilities does not need alone building,saving equipment investment,reducing the treatment costs of flue gas pollutants.Denitrification efficiency of the process can be over $60 \%$.Therefore,combinating the characteristics that $\mathrm{NO}_{\mathrm{X}}$ concentration of sintering flue gas is low,ozone oxidation simultaneous desulfurization and denitrification technology is reasonable.

\section{Sintering flue gas ozone oxidation simultaneous desulfurization and denitrification technology program}

To $400 \mathrm{~m}^{2}$ sintering machine,ozone oxidation simultaneous desulfurization and denitrification technology system mainly consists of lime slurry preparation system,absorber systems,ozone oxidation systems, the reaction product dewatering systems,process water systems,accident slurry systems,compressed air systems and automatic control system. The process is shown in Figure 1. 


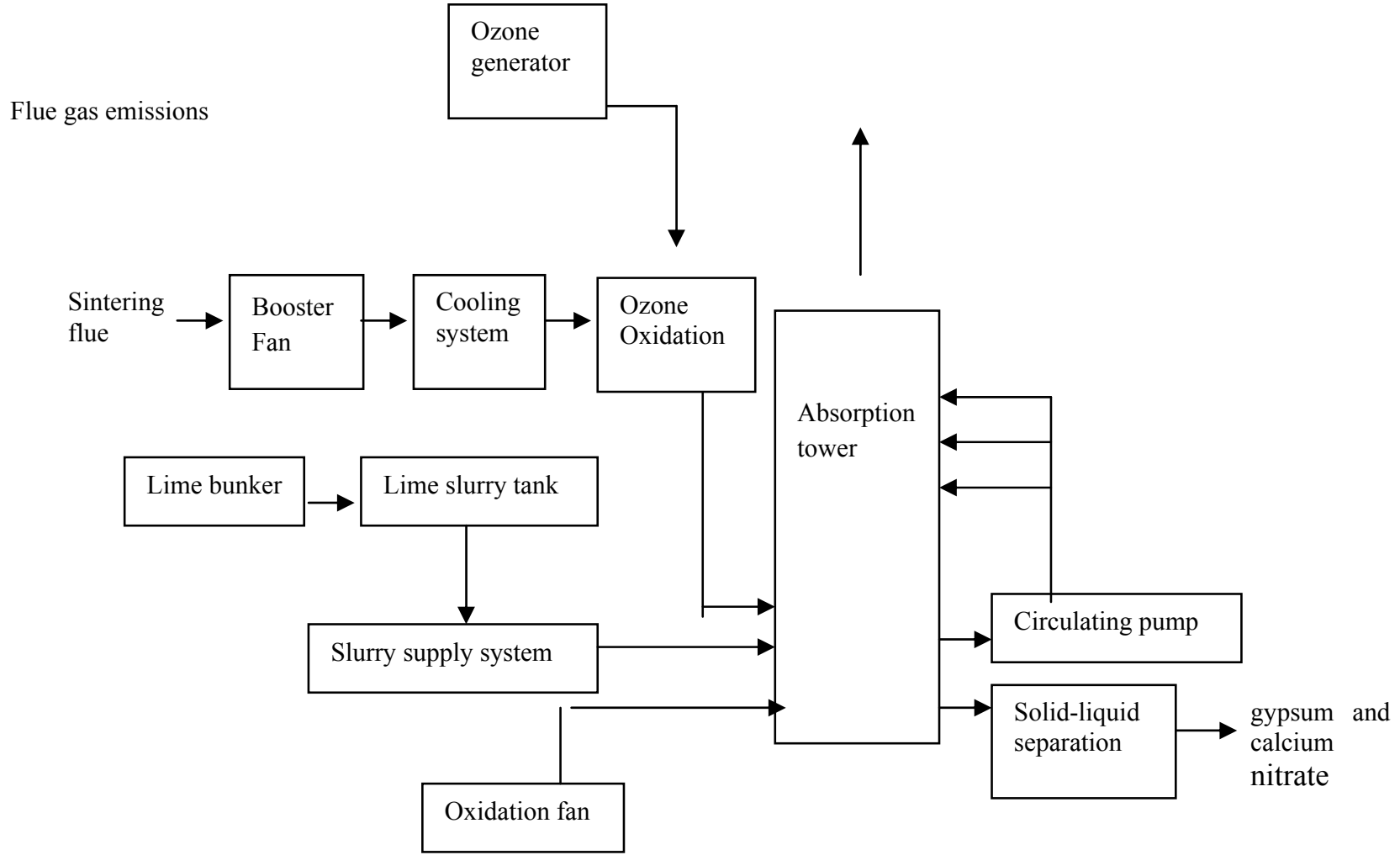

Figure 1. Ozone oxidation simultaneous desulfurization and denitrification process

Sintering flue gas is boosted by booster fans, and cooled by cooling system, then join ozone in the flue,the NO is oxidized to $\mathrm{NO}_{2}$. Flue gas is sent to absorber tower, the flue gas is contact with the absorbent slurry in the absorber tower, $\mathrm{SO}_{2}$ and $\mathrm{NO}_{2}$ is absorbed.After the water droplets in the flue gas is removed by a demister,flue gas is returned to the chimney emissions.

Lime slurry is pumped to the absorption section through the circulating pump,absorb $\mathrm{SO}_{2}$ and $\mathrm{NO}_{2}$ of flue gas.In the bottom of absorption tower, the reaction product is oxidized to $\mathrm{CaSO}_{4}$ and $\mathrm{Ca}\left(\mathrm{NO}_{3}\right)_{2}$ by bubbling air. $\mathrm{CaSO}_{4}$ and $\mathrm{Ca}\left(\mathrm{NO}_{3}\right)_{2}$ slurry discharged from the crystallization zone,after the solid-liquid separation, becomes gypsum and calcium nitrate solids.

\section{Analysis of the economic and environmental benefits}

To $400 \mathrm{~m}^{2}$ sintering machine,flue gas volume is $110 \times$ $10^{4} \mathrm{~m}^{3} / \mathrm{h}$, the initial concentration of $\mathrm{NO}_{\mathrm{X}}$ in flue gas is 400 $\mathrm{mg} / \mathrm{m}^{3}$, denitration efficiency is $50 \%$.

\subsection{Economic Benefit Analysis}

Operating costs are mainly absorbent material and power consumption.Operating costs of various expenses are shown in Table 1.

\subsection{Environmental Benefit Analysis}

After the denitrification projects of production line put into operation,the denitration efficiency can exceed $50 \%$.Denitrification system can reduce nitrogen oxide emissions by about 1584 tons/year,which can effectively improve the atmosphere that the iron and steel business is located in,environmental benefits and social benefits is significant.

Table 1. Statistics of operating costs

\begin{tabular}{c|c|c|c|c}
\hline No. & Name & Unit & Quatity & Cost \\
1 & Lime consumption & thousand yuan /year & 59 \\
2 & Power consumption & kw/a & 1951 & $526 \times 10^{4}$ \\
3 & Labor costs & number & 32 & 95 \\
4 & Equipment maintenance & ten thousand yuan /a & & 35 \\
\hline
\end{tabular}

As the table shows, the total operating costs of the production line denitration system is 652 million/year(Production Days of the production line is 300 day/year ). 


\section{Conclusions}

Ozone oxidation simultaneous desulfurization and denitrification technology is suitable for sintering flue gas.Using this denitration technology, $\mathrm{NO}_{\mathrm{X}}$ concentration of the sintering flue gas can achieve "Steel sintering and pelletizing industry air pollutant emission standards" (GB 28662-2012)requirements. At the same time achieving the targets that the investment of denitrification system for sintering flue gas is reasonable, environmental benefits are obvious.

\section{Acknowledgements}

This work was financially supported by Hebei colleges and universities of science and technology research projects (Z2015045),Qinhuangdao Science and Technology Research and Development Projects (201401A233,201401A006,201502A005).

\section{References}

[1] The Ministry of Environmental Protection.GB 28662-2012 Steel sintering,pelletizing industrial air pollutant emission standards[S].Beijing:China Environmental Science Press,2012.

[2] Jin Yonglong. Parsing mechanism of NOx formation during sintering $[\mathrm{J}]$. Sintered pellets, 2004,29( 5): 6-8.

[3] Liu Dajun,Wei Youquan,Yang Liqin.Research of emissions reduction situation of nitrogen oxide in China's steel production enterprises[J].Environmental Engineering,2012,30(5):118- 123.

[4] Duan Chuanhe, Xia Huaixiang.Coal-fired power plant flue gas DeNOx SCR engineering technology[M]. Beijing:China Electric Power Press, 2009:19-21.

[5] Yang Dong,XU Hong.SCR DeNOx technology and its application in coal-fired power plants[J].Electricity Environment and Protection,2007,23 (1):49-51.

[6] Sun Keqin,Han Xiang.Coal-fired power plant flue gas DeNOx equipment and operation [M].Beijing:China Machine Press,2011:20-22. 